\title{
Application of MEMS Microphone Array Technology to Airframe Noise Measurements
}

\author{
William M. Humphreys, Jr. ${ }^{*}$, Qamar A. Shams ${ }^{\dagger}$, Sharon S. Graves, \\ Bradley S. Sealey ${ }^{\S}$, Scott M. Bartram ${ }^{\pi}$, and Toby Comeaux ${ }^{\S}$ \\ NASA Langley Research Center, Hampton, Virginia, 23681
}

\begin{abstract}
Current generation microphone directional array instrumentation is capable of extracting accurate noise source location and directivity data on a variety of aircraft components, resulting in significant gains in test productivity. However, with this gain in productivity has come the desire to install larger and more complex arrays in a variety of ground test facilities, creating new challenges for the designers of array systems. To overcome these challenges, a research study was initiated to identify and develop hardware and fabrication technologies which could be used to construct an array system exhibiting acceptable measurement performance but at much lower cost and with much simpler installation requirements. This paper describes an effort to fabricate a 128-sensor array using commercially available Micro-Electro-Mechanical System (MEMS) microphones. The MEMS array was used to acquire noise data for an isolated $26 \%$-scale high-fidelity Boeing 777 landing gear in the Virginia Polytechnic Institute and State University Stability Tunnel across a range of Mach numbers. The overall performance of the array was excellent, and major noise sources were successfully identified from the measurements.
\end{abstract}

\section{Nomenclature}

A $\quad=$ shear layer amplitude correction

$\Delta t \quad=$ shear layer ray path time correction

$\hat{e} \quad=$ array steering vector, see equation (4)

$f \quad=$ frequency, $\mathrm{Hz}$

$\hat{G} \quad=$ cross spectral matrix

$\hat{G}_{\text {diag }=0} \quad=$ cross spectral matrix with diagonal removal

$k \quad=$ acoustic wave number, $\mathrm{ft}^{-1}$

$M \quad=$ total number of array microphones

$N \quad=$ number of data blocks

$P(\hat{e}) \quad=$ array output power for steering vector $\hat{e}$, see equation (5)

$r^{o}, r_{m}^{o} \quad=$ distance from source to $\vec{x}_{c}$ and $\mathrm{m}^{\text {th }}$ microphone, $\mathrm{ft}$

$r, r_{m} \quad=$ distance from steering location to $\vec{x}_{c}$ and $\mathrm{m}^{\text {th }}$ microphone, $\mathrm{ft}$

\footnotetext{
* Senior Research Scientist, Aeroacoustics Branch, Senior Member AIAA.

${ }^{\dagger}$ Senior Research Scientist, Aeronautics Systems Engineering Branch.

* Senior Research Scientist, Aeronautics Systems Engineering Branch, Senior Member AIAA.

${ }^{\S}$ Research Technician, Aeronautics Systems Engineering Branch.

${ }^{\Uparrow}$ Research Technician, Advanced Sensing and Optical Measurements Branch.
} 


$\begin{array}{ll}W\left(k, \vec{x}, \vec{x}^{o}\right) & =\text { ideal array response, see equation (1) } \\ W_{s} & =\text { hamming window weighting } \\ \vec{x} & =\text { Cartesian coordinate, } \mathrm{ft} \\ \vec{x}_{c} & =\text { array phase center, } \mathrm{ft} \\ X_{i k}(f) & =\mathrm{k}^{\text {th }} \text { FFT data block for } \mathrm{i}^{\text {th }} \text { microphone, see equation (3a) } \\ \vec{x}_{m} & =\text { distance vector from steering location to } \mathrm{m}^{\text {th }} \text { microphone, } \mathrm{ft} \\ \omega & =\text { angular frequency }(=2 \pi f), \text { radians } / \text { second }\end{array}$

\section{Introduction}

$\mathrm{R}$ ECENT research in noise reduction during aircraft approach and landing has resulted in the development of technologies which have resulted in measurable declines in the noise generated by airframe structures. Most notable among these are noise reduction devices involving components of the high-lift system; i.e., leading edge slats and trailing edge flaps. ${ }^{1-3}$ Similar technologies are currently being introduced to reduce noise generated by the aircraft undercarriage ${ }^{4}$, with the ultimate goal of allowing not only adherence to Stage 3 and 4 noise rules ${ }^{5}$ but also meeting challenging noise reduction milestones specified in the NASA Vehicle Systems Program. The successful development of these reduction technologies has relied not only on physics-based modeling of noise generation mechanisms, but also on acquisition of quantitative databases of noise measurements with which to validate the models. Over the past several years, significant effort has been expended acquiring noise databases using microphone directional array (DA) instrumentation. The current generation of this instrumentation is capable of extracting accurate noise source location and directivity on a variety of airframe components using sophisticated data reduction algorithms. ${ }^{6-8}$

The gains in test productivity using DA instrumentation have been significant, and this has resulted in the desire to install larger and more complex array systems not only in anechoic facilities but also in closed reverberant wind tunnels. Several challenges occur with such installations:

1. The per-channel cost of the installation can be prohibitive. Traditional DA hardware, consisting of sensors composed of individual commercial condenser microphone / preamplifier / power supply combinations, can be too expensive to implement more than a few dozen to perhaps a couple hundred channels of acquisition.

2. Installation of the microphones can be complicated, especially in hard-walled wind tunnel test sections. Directional array beamforming techniques rely on accurate knowledge of the placement of the sensors, and the required location accuracy can be difficult to achieve with large arrays.

3. Numerous expensive cables may be required to connect the microphones to the signal conditioning and acquisition systems. Current generation arrays often require that a separate cable be run for each microphone.

4. The signal conditioning and digitization hardware can be complex and expensive, given the large number of data channels to acquire.

To overcome these challenges, a research study was initiated to identify and develop hardware and fabrication technologies that could be used to construct a DA system exhibiting measurement performance comparable to the current generation of arrays, but at significantly lower cost and with simpler installation requirements. The authors have previously reported their experience with development of low-cost array technology based on commerciallyavailable electret condenser microphones. ${ }^{9}$ The present study involved the fabrication and performance analysis of an array using commercially-available Micro-Electro-Mechanical System (MEMS) sensors which could easily be installed in closed reverberant wind tunnels. The objectives of the research study were:

1. Characterize the acoustic response of a suitable MEMS microphone via laboratory calibration and evaluate its suitability for DA use,

2. Develop and evaluate methods to install MEMS microphones in ground test facilities quickly and efficiently,

3. Integrate commercially-available signal conditioning and data acquisition hardware with the MEMS array and evaluate the performance of the data system,

4. Evaluate the beamforming performance of the MEMS array, and

5. Use the MEMS array to obtain aeroacoustic data on a relevant airframe noise model. 
This paper describes the design and fabrication of the array components, characterization of the individual microphones, and use of the array to obtain aeroacoustic data on a suitable airframe model, in this case a $26 \%$ scale, high-fidelity Boeing 777 landing gear.

\section{MEMS Array Construction}

The generic details regarding the construction of a MEMS microphone array are described below. Specific details regarding construction of the array system used in the landing gear test campaign will be described shortly.

\section{A. Microphones}

A systematic search was conducted to identify suitable commercial off-the-shelf microphones which could be used to construct a high density array with minimal cost. Given the rapid pace of micro-fabrication technology development, the authors chose to limit their search to MEMS microphones which could be obtained in quantity. Several MEMS microphone designs which exhibit characteristics suitable for DA use have been described in the literature, the most notable being those of Sheplak ${ }^{10}$, Saini ${ }^{11}$, Arnold ${ }^{12}$, and Schafer. ${ }^{13}$ After considering candidate devices, the authors chose to use Knowles Acoustics SP0101NZ silicon microphones as the sensing elements in the array. ${ }^{*}$ Figure 1a shows a photograph of the SP0101NZ microphone, housed in a 6.15- by 3.75-mm enclosure. The microphone uses a floating diaphragm with perforated backplane that is recessed behind a 0.9-mm circular orifice. The microphone incorporates a charge pump circuit consuming less than $0.5 \mathrm{~mA}$ of current when powered with a 5 volt supply. Figure $1 \mathrm{~b}$ shows a back view of the microphone illustrating the placement of contacts on the rear of the device, while Figure 2 depicts the manufacturer's published sensitivity response of a typical device over a frequency range of $100 \mathrm{~Hz}$ to $10 \mathrm{kHz}$. The microphones are designed primarily for cell phone use, and thus are optimized for the lower audio frequency range.

\section{B. Mounting and Interconnect Architecture}

One of the innovations incorporated into the MEMS array was the design of a unique mounting architecture. A flexible polyimide circuit board was chosen as the base for mounting and connecting the microphones in the array. The flexible circuit board consists of a patterned arrangement of printed wiring on a pliable base material. These boards share many characteristics with their rigid counterparts, but can be manufactured to be thin (as thin as $0.1 \mathrm{~mm}$ in some cases) and to reduce the weight of the packaging (by as much as 75 percent).

Kapton was chosen as the flexible mounting base for the arrays constructed for this study. To facilitate the construction of large array patterns, individual Kapton sheets could be fabricated in sections and fitted together to form a final array. Each flexible sheet was composed of a base laminate layer sandwiched between two coverlay layers. The MEMS microphones were connected to the Kapton sheets via solder pads built into the printed wiring on the sheets. A single bus line powered all microphones from a common supply, and the microphone output signals were transmitted from the Kapton using one or more data buses. To minimize cross talk between array channels, all output data lines embedded in the Kapton were shielded with ground lines interposed between each data line. This construction resulted in a maximum interchannel cross talk level of approximately $-40 \mathrm{~dB}$. Figure 3 shows a prototype Kapton sheet containing 63 attached microphones. Although MEMS microphones were attached to the sheets for this study, it is noted that any suitable microphone with rear contact pads (e.g., the electret microphones described in reference 9) could be mounted in a similar fashion.

To accommodate hard-walled tunnel installations, the Kapton sheets were designed to be bonded directly to a rigid surface (such as a test section wall) and covered with a face plate containing exact cutouts for the microphones, thereby providing a smooth flush-mounted surface for the face of the array. G10/FR4 circuit board material manufactured from a continuous glass woven fabric base impregnated with an epoxy resin binder was chosen for the face plate. This particular material was chosen due to its high mechanical strength, good dielectric loss properties, and good electric insulation properties, allowing the material to withstand the harsh conditions encountered in wind tunnel testing and thus protect the underlying Kapton circuitry. Figure 4 shows a cross section diagram of the completed array "sandwich" construction.

\footnotetext{
* Specific manufacturer's names are explicitly mentioned only to accurately describe the research performed. The use of manufacturer's names does not imply an endorsement by the U.S. Government nor does it imply that the specified equipment is the best available.
} 


\section{Signal Conditioning and Digitization Hardware}

The signal conditioning hardware developed for use with the array consisted of customized line drivers and antialiasing filters. The line drivers were constructed using low supply current, high gain-bandwidth LM6144 operational amplifiers designed to transmit the microphone signals from the array to the filtering and digitization hardware. Signals could be successfully transmitted several dozen feet using the drivers. Figure 5 shows a photograph of a set of line drivers attached to the back of one of the array panels.

The anti-alias filtering hardware consisted of two motherboards into which were inserted a total of 128 small daughter boards each containing a separate lowpass filter circuit. Figure 6 shows a picture of the compute system including the external supplies which powered the filters. The mother / daughter board design resulted in a modular system which was easy to debug and service, and which enabled the filter characteristics to be changed by swapping daughter boards with ones containing different filter parameters. The characteristics of the filters were determined by selecting appropriate values of resistors connected to a Maxim MAX274 filter chip socketted on each daughter board. For the present study, a lowpass Chebyshev filter with cutoff frequency of $20 \mathrm{kHz}$ was employed for each data channel.

The filter outputs were passed to a distributed hardware system used to digitize and store the signals generated by the array microphones. Two Pentium-class PC's were fitted with individual commercially-available 64-channel digitization cards. Figure 7 shows a picture of the resultant acquisition system. The two acquisition cards were synchronized externally to allow simultaneous sampling of 128 channels, at a maximum sampling rate of $200 \mathrm{kHz}$ per channel. Customized software was developed to allow complete control of the acquisition process while providing real-time display of individual data channels.

\section{Microphone Characterization}

An important goal of the present study was to conduct a careful characterization of an ensemble of SP0101NZ MEMS microphones to ascertain their suitability for array use. Four different types of calibration data were obtained - the 200-Hz sensitivity for each microphone, the broadband pressure response (magnitude and phase) for each microphone, the background noise level for a typical microphone, and the effect of environmental changes (in this case percent humidity) on the sensitivity of a typical microphone.

\section{A. Sensitivity}

Figure 8 shows a histogram of the $200-\mathrm{Hz}$ sensitivity distribution for an ensemble of 200 microphones. The sensitivity of each microphone was determined using a standards-traceable Bruel and Kjaer 4226 multifunction calibrator generating a 94-dB sound pressure level (SPL) signal, relative to a reference pressure of 20 microPascals $(\mu \mathrm{Pa})$. The calibrator was externally driven with a 0.1 -volt peak-to-peak, $200-\mathrm{Hz}$ sinusoidal signal produced by an arbitrary waveform generator. The sensitivity of each microphone was defined as the calibration value (specified in units of millivolts / Pascal) which when applied to the output of the microphone allowed it to indicate an SPL of exactly $94 \mathrm{~dB}$ at $200 \mathrm{~Hz}$. As can be seen in the figure, there is an approximate Gaussian distribution of sensitivities centered around a value of $9.5 \mathrm{mV} / \mathrm{Pa}$, with the majority of the microphones having sensitivities between 7 and $12 \mathrm{mv} / \mathrm{Pa}$. Given the low cost of the MEMS microphones it is a simple matter to measure the 200-Hz sensitivities of a large sample of devices and then choose those with matched characteristics. This procedure was not followed for the present study, and instead the individual measured sensitivities of the MEMS microphones were accounted for during analysis of acquired data.

\section{B. Broadband Pressure Response}

The broadband pressure response of each MEMS microphone was obtained over the frequency range of $200 \mathrm{~Hz}$ to $20000 \mathrm{~Hz}$ using the same multifunction calibrator used for the sensitivity characterization, with one important difference - the calibrator was modified to allow access to the transducer driving signal, allowing measurement of both the magnitude and phase response of the microphones. A special nylon and stainless steel adapter was fabricated to allow accurate insertion and registration of the microphones into the calibrator with minimal acoustic loss. The calibrator was externally driven using a 0.1-volt peak-to-peak sinusoidal signal varying in frequency from $200 \mathrm{~Hz}$ to $20000 \mathrm{~Hz}$ in 200-Hz steps. The driving and microphone output signals were recorded on a two-channel transient data recorder using a per-channel sampling rate of $120 \mathrm{ksamples} / \mathrm{sec}$. The magnitude and phase response of each microphone were computed using Welch's averaged periodogram method. ${ }^{14}$

Figure 9 shows the responses obtained using the technique described above for 10 representative microphones. The magnitude response is referenced to the baseline $200-\mathrm{Hz}$ sensitivity value for each microphone. As can be seen in the figure, the ensemble of magnitude responses matched to within $\pm 1 \mathrm{~dB}$ at any one particular frequency while 
the phases matched to within \pm 10 degrees. The microphones are designed to exhibit a flat response over a frequency range of $100 \mathrm{~Hz}-10 \mathrm{kHz}$, and indeed this is verified by the data shown in Figure 9. The microphones will operate at higher frequencies; however, a broad resonance peak occurring at approximately $14 \mathrm{kHz}( \pm 2 \mathrm{kHz})$ severely limits performance of the devices at these frequencies. Nevertheless, the phase response shown in the figure implies that an array populated with these devices will yield a proper beamform response without the need for phase corrections as long as the frequency examined does not exceed 10-12 kHz. Mosher et.al. discusses phase matching criteria for array microphones in greater detail. ${ }^{15}$

\section{Background Noise Measurement}

The background noise level of a representative MEMS microphone was determined using a vacuum-isolation chamber mounted on a vibration-damped table. ${ }^{16}$ The vacuum chamber consisted of an inner chamber maintained at ambient conditions into which the MEMS microphone was placed. The inner chamber was then suspended inside an outer evacuated chamber to provide a high degree of acoustic isolation from the surrounding environment. Figure 10 illustrates the background noise autospectrum obtained for a single vacuum pressure. As can be seen in the figure, classic 1/f noise dominates the spectrum at low frequency. The large spike in the spectrum at $15.6 \mathrm{kHz}$ is due to the scan frequency of the monitor attached to the data acquisition computer. The source of the spikes at 5.9 and $8.2 \mathrm{kHz}$ has not been identified. At higher frequencies, the background noise is approximately 15 to $18 \mathrm{~dB}$ (re $20 \mu \mathrm{Pa}$ ). This compares with 10 to $12 \mathrm{~dB}$ for high quality quarter-inch commercial condenser microphones. The noise spectrum shown in Figure 10 is similar in structure to electret condenser microphone background spectra measured by the authors (see reference 9).

\section{Environmental Sensitivity}

The airframe noise measurements conducted as part of this study implied that the MEMS microphones would be subjected to large variations in temperature and humidity. To quantify the change in microphone sensitivity as the external environment (in this case humidity) was varied, a series of measurements were conducted in a test chamber in which highly stable temperature and humidity levels could be maintained. A Bruel and Kjaer 4226 multifunction calibrator was mounted in the chamber and used to calibrate in-situ a representative MEMS microphone plus a commercial quarter-inch condenser microphone used as a reference. Four different humidity levels at a constant temperature of $104{ }^{\circ} \mathrm{F}$ were selected for the test. Figure 11 shows the resultant variation in microphone sensitivity for the MEMS and reference microphones. The roll-off in sensitivity below $100 \mathrm{~Hz}$ denoted in the figure for the MEMS device is postulated to be due to the device packaging, while the increase in sensitivity above $6 \mathrm{kHz}$ represents the beginning of the resonance peak discussed in section IIIb. Nevertheless, these MEMS microphones are relatively insensitive to changes in percent humidity for constant temperature, as can be inferred from comparing the two sets of data shown in the figure.

\section{Airframe Noise Application}

One of the main objectives of the present study was to acquire noise source location and strength data for a relevant airframe noise model using a high-density MEMS array. The selected airframe noise test consisted of measurements on a 26\%-scale, high-fidelity Boeing 777 main landing gear model, installed in the Stability Tunnel at the Virginia Polytechnic Institute and State University (Virginia Tech or VT). This particular model had been extensively tested previously at NASA Ames Research Center, and a good database of baseline noise data exists for the model (see references 3 and 4). A brief description of the VT test facility, the model, the array design and installation, and representative data acquired with the MEMS array follows.

\section{A. Test Facility}

The VT Stability Tunnel is a closed circuit wind tunnel with interchangeable round and square test sections approximately 24 feet in length. ${ }^{17}$ The cross sectional dimensions of the square test section are 6 by 6 feet. The tunnel is powered by a 600 horsepower DC motor. The maximum free stream velocity obtainable in the square test section is $275 \mathrm{ft} / \mathrm{sec}$, with a maximum Reynolds number per foot of $1.66 \times 10^{6}$. The control room and shop area for the tunnel are housed inside the plenum chamber. Figure 12 shows a diagram of the tunnel layout.

\section{B. Model}

Figure 13 shows a photograph of the landing gear model mounted in the VT Stability Tunnel square test section. The model was a high-fidelity landing gear which faithfully reproduced full-scale features to an accuracy of better than 0.2 inches. The load bearing portions of the model consisted of a steel truck and wheel assembly which was 
mounted to a steel strut attached to the floor of the test section. Stereo lithography was used to create small-scale detailed structures which were then attached to the model (e.g., cable harnesses, hydraulic actuators, etc.). Hydraulic lines were simulated using electrical wires of various gauges and attached to the model. The wheels on the landing gear truck were individually removable, and the truck angle could be continuously varied from approximately -3 to +13 degrees (with respect to the free stream flow direction). References 3 and 4 contain more detailed information concerning specific aspects of the model.

\section{Array Pattern}

The array microphone pattern chosen for this study consisted of a multi-arm, equal-aperture-area logarithmic spiral design containing 128 microphones. ${ }^{6,18,19}$ Figure 14 illustrates the pattern, with the microphone coordinates listed in Appendix I. The outermost microphone to microphone diameter was 32 inches. Given an average source to observer distance of 36 inches when measuring components of the landing gear in the VT Stability Tunnel, this pattern yielded a total solid collecting angle for the array of 132 degrees. The large array size allowed more source region detail to be revealed, but at the expense of increased errors in the measured source levels. ${ }^{20}$ Nevertheless, accurate total noise source levels were retrievable using integration and DAMAS processing algorithms for the majority of data acquired with the array.

To enable easier addressing of individual microphones by the data acquisition system described in section IIc, the 128-microphones in the array pattern were arranged into two separate 64-element subarrays (denoted as the blue and red subarrays). The blue subarray consisted of all microphones situated in the odd-numbered rings of the array pattern, with the innermost ring denoted as ring 1 . The red subarray consisted of all microphones situated in the even-numbered rings. Each of the two computers in the data acquisition system were connected to individual subarrays and were denoted as the red and blue acquisition nodes. Synchronization of the red and blue acquisition nodes allowed simultaneous collection of data from all 128 microphones in the array. Data could also be acquired on demand from only one subarray.

\section{Theoretical Array Performance}

Characterization of array performance was conducted by examining the theoretical response of the array to an ideal simple source. Based on monopole source theory, the ideal response of the array can be expressed as ${ }^{21}$

$$
W\left(k, \vec{x}, \vec{x}^{o}\right) \equiv \sum_{m=1}^{M} \frac{r^{o}}{r_{m}^{o}} e^{j k\left[\left(r^{o}-r\right)-\left(r_{m}^{o}-r_{m}\right)\right]}
$$

where $\vec{x}$ is an arbitrary Cartesian location in space to which the array is electronically steered, $\vec{x}^{o}$ is the source location, $r^{o}$ and $r_{m}{ }^{o}$ are the distances from the source to $\vec{x}_{c}$ and the $\mathrm{m}^{\text {th }}$ microphone, respectively, and $r$ and $r_{m}$ are the distances from the steering location to $\vec{x}_{c}$ and the microphone, respectively. The response shown in equation (1) is normally expressed in decibels referenced to the level obtained at $\vec{x}^{o}$

$$
d B(\vec{x})=20 \log _{10}\left[\frac{\left|W\left(k, \vec{x}, \vec{x}^{o}\right)\right|}{\left|W\left(k, \vec{x}^{o}, \vec{x}^{o}\right)\right|}\right]
$$

Figure 15 depicts the array beamwidth (defined by the half-power points of the main lobe of the array response) versus frequency for an ideal monopole source located three feet directly in front of the array. The beamwidth was computed using equations (1) and (2) for a horizontal scanning line positioned at the source distance in front of the array. As expected, the beamwidth decreases rapidly as the frequency increases, approaching a rough asymptote of 1.5 inches at $20 \mathrm{kHz}$. Figure 16 depicts the theoretical response of the array to an ideal monopole source placed at a distance of three feet directly in front of the array, again using equations (1) and (2) and computed over a vertical scanning plane located at the source distance. The response for frequencies of $2.5,6.3,8.0$, and $10.0 \mathrm{kHz}$ are shown for comparison. As expected for the log-spiral array design, a rich pattern of sidelobes appears around the main lobe as the frequency is increased. Nevertheless, the peak sidelobe to main lobe ratio never exceeds $-12 \mathrm{~dB}$ for the four frequencies shown in the figure. This is a particularly important design specification, since the use of the array in a reverberant wind tunnel test section necessitates that rejection of unwanted reflected ray paths be maximized. 


\section{E. Array Mounting}

Due to the size of the microphone pattern, three separate Kapton flexible circuit sheets were fabricated and fitted together as shown in Figure 17 to form the complete array. The Kapton sheets were bonded to an aluminum backplate designed to fit into one of the test section wall panel locations in the tunnel. The Kapton sheets containing the microphones were sandwiched between the aluminum backplate and a face sheet constructed of G10/FR4 circuit board material, as described in section IIb. Three separate array panels were fabricated for this study, and Figure 18 shows one of the completed panels.

To shield the microphones from the direct influence of the test section boundary layer pressure fluctuations (a particular concern with the VT Stability Tunnel due to the length of the test section), the array backplate was designed to be recessed one inch behind a Kevlar sheet which was stretched across the array such that when the backplate was mounted in the tunnel test section, the Kevlar would maintain the wall integrity while shielding the microphones from the boundary layer. This was a very similar mounting technique to that used by Jaeger et.al. for closed test section array measurements in the 7- by 10-foot Wind Tunnel at Ames Research Center. ${ }^{22,23}$ The recessed mounting design for the VT Stability Tunnel resulted in exceptionally better performance of the array to identify noise sources in the tunnel versus earlier flush-mounted designs which were tried. It is noted that the mounting frame used to attach the Kevlar to the array intruded too close to the outer ring of microphones in the array. Hence, the outer ring was discarded during data analysis, effectively yielding an array utilizing 112 microphones. The beamwidths shown in Figure 15 increased by $8.7 \%$ due to the smaller array aperture size, but in general the operation and performance of the array were unaffected by the discarding of the outer 16 microphones.

\section{F. Data Acquisition and Reduction}

Two 25-second acquisition runs using a per-channel sampling rate of $50 \mathrm{kHz}$ were performed for all data collected for this study. Post processing of acquired array data began with the computation of an $M x M$ crossspectral matrix (CSM) for each ensemble of data, where $M$ is the total number of microphones in the array. The computation of the individual matrix elements was performed using Fast Fourier Transforms (FFT) of the original data ensemble. This was done after converting the raw data to engineering units. The time data were segmented into a series of non-overlapping blocks each containing 2048 samples. Using a Hamming window, each of these blocks of data was Fourier transformed into the frequency domain with a frequency resolution of $24.4 \mathrm{~Hz}$. The individual cross spectrum for microphones $i$ and $j$ was computed via

$$
G_{i j}(f)=\frac{1}{N W_{s}} \sum_{k=1}^{N}\left[X_{i k}^{*}(f) X_{j k}(f)\right]
$$

where $W_{S}$ is the Hamming window weighting constant, $N$ is the number of blocks of data, and $X$ is an FFT data block. The full CSM was formed as

$$
\hat{G}=\left[\begin{array}{cccc}
G_{11} & G_{12} & \cdots & G_{1 M} \\
& G_{22} & & \vdots \\
& & \ddots & \vdots \\
& & & G_{M M}
\end{array}\right] .
$$

The lower triangular elements of this Hermitian matrix were computed by taking the complex conjugates of the upper triangular elements. The diagonal terms were removed to improve the spectral dynamic range by subtracting off self-noise dominated auto-spectra during the beamforming process (see chapter 1 of reference 6).

A classic delay and sum beamforming approach was used for the initial analysis of the array data. This approach assumed distributions of monopoles for the measured sources. In delay and sum beamforming, the array is electronically "steered" to a series of chosen source locations. For each selected steering location, a steering vector $\hat{e}$ containing a retarded time phase adjustment for each microphone in the array was defined as 


$$
\hat{e}=\left[\begin{array}{c}
A_{1} \frac{r_{1}}{r_{c}} \exp \left\{j\left[\left(\vec{k} \cdot \vec{x}_{1}\right)+\omega \Delta t_{1, \text { shear }}\right]\right\} \\
\vdots \\
A_{M} \frac{r_{M}}{r_{c}} \exp \left\{j\left[\left(\vec{k} \cdot \vec{x}_{M}\right)+\omega \Delta t_{M, \text { shear }}\right]\right\}
\end{array}\right]
$$

where $\vec{k}$ is the acoustic wave vector, $\vec{x}_{m}$ is the distance vector from the steering location to each microphone $m, \omega$ is the angular frequency, and the ratio $\left(r_{m} / r_{c}\right)$ is included to normalize the distance related amplitude to that of the phase center of the array. Equation (4) contains terms to account for mean amplitude and phase changes due to refraction of the sound as it passes through the tunnel wall boundary layer and Kevlar sheet to the individual microphones in the array. The geometry of the refracted ray path and the correction terms were calculated by the use of Snell's law and Amiet's method. ${ }^{24}$ For simplicity, it was assumed that the boundary layer was infinitesimally thin and that its location was defined by the surface of the Kevlar sheet. Transmission losses due to the passage of the sound through the Kevlar were not included in the present analysis.

The output power spectrum (or response) of the array at the steering location was obtained from

$$
P(\hat{e})=\frac{\hat{e}^{T} \hat{G}_{d i a g=0} \hat{e}}{M^{2}-M}
$$

where the superscript $T$ denotes a complex transpose of the matrix, and $P(\hat{e})$ is a mean-squared-pressure quantity. The division by $M^{2}-M$ serves to reference the array output level to an equivalent single microphone output level. It was anticipated that poor signal-to-noise conditions would be encountered in the wind tunnel due to contamination of the microphone signals by exposure to the tunnel boundary layer (even when recessed behind Kevlar). Thus, equation (5) has been modified from its standard form to denote that a modified version of the CSM is employed where the diagonal terms have been removed. Reference (7) provides greater detail concerning the classical processing performed on the array data.

In addition to classic delay and sum beamforming, the DAMAS deconvolution algorithm was applied to selected datasets to allow accurate source distributions to be identified by removing the effects of the array point spread function from the beamformer output. ${ }^{25,26}$ This was done using iterative solution of a system of linear equations accounting for reciprocal influences of the array response at the various locations over the array beamform survey region. After deconvolution, the integrated noise radiated from regions of interest were determined via a simple summing of mean-squared pressures over each region.

\section{G. Representative Results}

Noise data were obtained on the landing gear model with the Kevlar-covered MEMS array mounted in both the test section ceiling (for truck flyover viewing) and the test section sidewall (for strut brace viewing). Figure 19 shows photographs of the array mounted in each position. Baseline data were acquired at a number of freestream Mach numbers spanning a range of 0.12 to 0.17 for a range of gear truck angles spanning -3 to +13 degrees. Only baseline data obtained for a truck angle of +13 degrees and a Mach number of 0.17 are presented here.

Flyover View: Figure 20 depicts the beamformer scanning geometry employed when the array was mounted in the ceiling of the test section for flyover viewing of the gear truck assembly. A series of six separate 2D planes each oriented parallel to the face of the array were defined as shown in the figure. Each plane extended 50 inches in both the streamwise and spanwise directions, and were centered (approximately) on the truck assembly. Each plane was designed to cut through the truck at several different vertical locations extending from the top of the trailing edge wheels to slightly below the trailing edge cable harness. For each plane, standard delay and sum beamforming using CSM diagonal removal (as defined by equations 3 through 5) was performed to identify significant noise regions for a number of one-third octave frequency bands. Figure 21 shows the results of this analysis for the $6.3-\mathrm{kHz}$ one-third octave band, with a separate contour plot presented for each of the six examined beamforming planes. A number of strong noise sources can clearly be identified in each plane. Note that due to the limited depth resolution of the array, sources identified at similar streamwise and spanwise locations in more than one plane may not be independent of one another, but may represent different views of the same source. Nevertheless, it is clear that there 
are dominant noise sources appearing in the vicinity of several of the axle and brake assemblies on the truck. It also appears that the leading edge cable harness contributes significant noise as viewed in the 33- through 48-inch beamforming planes. It is unclear why the noise sources depicted in Figure 21 are not positioned symmetrically about the gear truck, but as will be seen, this effect is also observed when the array is moved to the sidewall location.

Note that the strong sources revealed at the 6 and 12 o'clock positions in the figure are postulated to be ones generated by the gear strut and braces and reflected off the floor and sidewalls of the test section. It is quite likely that these reflections are corrupting the measured sound pressure levels around the landing gear, since they intersect a large number of array sidelobes. The implementation of techniques to remove the influence of these reflections on the measured SPL's was beyond the scope of the present study, and is a topic for future work.

Strut Brace View: Figure 22 depicts the beamformer scanning geometry employed when the array was mounted in the sidewall of the test section for viewing the gear strut and brace assembly. A series of six separate vertical 2D planes each oriented parallel to the face of the array were defined as shown in the figure. Each plane extended 50 inches in both the streamwise and vertical direction, and was centered (approximately) on the point where the main braces connect with the strut. Each plane was designed to cut through the gear at several locations extending from five inches in front of the port-side wheels (to obtain a slice through the lower braces) to behind the starboard-side wheels. As with the flyover position data processing, standard beamforming using CSM diagonal removal was performed for a number of one-third octave frequency bands. In addition, DAMAS processing was performed on the data to reveal hidden details of noise sources obscured by the array point spread function. Figure 23 shows the results of the standard beamform analysis for the $6.3-\mathrm{kHz}$ one-third octave band. As before, a separate contour plot is presented for each of the six vertical beamforming planes. An examination of Figure 23 reveals clear indication that for all beamforming planes, the interconnects between the strut and braces are the dominant noise sources. The strength of these sources could easily account for the strong sidewall reflections appearing in Figure 21. Also, the leading edge cable harness and front axle assembly contribute significant noise in those planes cutting through the center of the truck and the far wheels. The fact that the cable harness / axle noise is not symmetric about the center of the truck confirms the asymmetry observed in Figure 21, and could be partially due to scattering of sound around blocking structures on the gear.

Figure 24 shows the corresponding DAMAS output for the same planes and one-third octave band depicted in Figure 23. While the source distributions shown in the first two planes (19 and 24 inches in front of the array) are not easily identified, it is interesting that for the next three planes $(29,33.5$, and 38 inches in front of the array) the brace assembly is clearly outlined by the location of the dominant sources. In particular, the secondary braces appear to generate significant noise, implying that modification of these structures may produce quantifiable noise reduction. The 43 -inch plane shows significant leading edge noise on the truck assembly, implying modification of this assembly may also provide noise reduction.

\section{Conclusions}

The need for deployment of ever larger microphone arrays for aeroacoustic testing continues to grow. The authors believe the present study has demonstrated that a high-density microphone array system can be constructed using commercially-available MEMS microphones, and that such a system can exhibit measurement performance comparable to the current generation of arrays, but at much lower cost and complexity. In particular, the MEMS array system fabricated for this study and used for aeroacoustic testing in the Virginia Tech Stability Tunnel possessed the following beneficial characteristics:

1. The per-channel cost of the installation of the array was significantly reduced.

2. The array panel was easily fabricated compared with traditional arrays.

3. The installation of the array in the tunnel was quite straightforward, with the time required to install the array in the test section being less than two hours.

4. The amount of support hardware for signal conditioning, transmission, and digitization was greatly reduced.

Quantitative noise measurements on a 26\%-scale landing gear model showed that the array performed on par with more conventional systems, and these measurements represent the first known use of a high-density MEMS array for aeroacoustic (in particular airframe) noise testing. The only significant problem with use of the system concerned the limited frequency range of the MEMS microphone due to an inherent resonance within the device. Consequently, operation of the array was restricted to frequencies less than 12-13 kHz. However, given the rapid 
pace of MEMS technology development, the authors are confident that higher frequency, lower cost microphones will be available in the near future and will allow greater use of MEMS array systems like the one presented here.

\section{Acknowledgments}

The authors would like to thank Dr. Ricardo Burdisso in the Department of Mechanical Engineering at Virginia Tech for his generosity in allowing the use of the Stability Tunnel and 26\%-scale landing gear for this study. The authors would also like to thank Patricio Ravetta and Hugo Camargo, PhD students at Virginia Tech for their assistance in the installation and operation of the MEMS array system, and Donald Harper of Swales Aerospace and William Chambers of the Langley Aeronautics Systems Engineering Branch for their assistance with the development and operation of the data acquisition system.

\section{References}

${ }^{1}$ Brooks, T. F., and Humphreys, W. M., Jr., "Flap-edge Aeroacoustic Measurements and Predictions", Journal of Sound and Vibration, vol. 261, pp. 31-74, 2003.

${ }^{2}$ Mendoza, J.M., Brooks, T. F., and Humphreys, W. M., Jr., “An Aeroacoustic Study of a Leading Edge Slat Configuration”, International Journal of Aeroacoustics, vol. 1, pp. 241-274, 2002.

${ }^{3}$ Horne, W. C., Burnside, N. J., Soderman, P. T., Jaeger, S. M., Reinero, B. R., James, K. D., and Arledge, T. K., “Aeroacoustic Study of a 26\%-Scale Semispan Model of a Boeing 777 Wing in the NASA Ames 40- by 80-Foot Wind Tunnel", NASA Technical Paper TP-2004-212802, October, 2004.

${ }^{4}$ Jaegar, S. M., Burnside, N. J., Soderman, P. T., Horne, W. C., and James, K. D., "Microphone Array Assessment of an Isolated, 26\%-Scale, High-Fidelity Landing Gear", NASA Technical Paper TP-2004-212815, November, 2004.

${ }^{5}$ Anonymous, “Airport Noise and Capacity Act of 1990”, 49 U.S.C. App. 2151-2158, 1990.

${ }^{6}$ Mueller, T. J. (editor), Aeroacoustic Measurements, Springer-Verlag, 2002.

${ }^{7}$ Humphreys, W. M., Jr., Brooks, T. F., Hunter, W. W., Jr., and Meadows, K. R., "Design and Use of Microphone Directional Arrays for Aeroacoustic Measurements", AIAA Paper 98-0471, 36 ${ }^{\text {th }}$ Aerospace Sciences Meeting and Exhibit, Reno, NV, 1998.

${ }^{8}$ Sijtsma, P., and Holthusen, H., "Source Location by Phased Array Measurements in Closed Wind Tunnel Test Sections", AIAA Paper 99-1814, $5^{\text {th }}$ AIAA/CEAS Aeroacoustics Conference, Seattle, WA, 1999.

${ }^{9}$ Humphreys, W. M., Jr., Gerhold, C. H., Zuckerwar, A. J., Herring, G. C., and Bartram, S. M., "Performance Analysis of a Cost-Effective Electret Condenser Microphone Directional Array", AIAA Paper 2003-3195, 9 ${ }^{\text {th }}$ AIAA/CEAS Aeroacoustics Conference, Hilton Head, SC, 2003.

${ }^{10}$ Sheplak, M., Breuer, K. S., and Schmidt, M. A., "A Wafer-Bonded, Silicon-Nitride Membrane Microphone with Dielectrically-Isolated Single Crystal Silicon Piezoresistors", Proceedings of the Solid-State Sensor and Actuator Workshop, pp. 23-26, 1998.

${ }^{11}$ Saini, R., Bhardwaj, S., Nishida, T., and Sheplak, M., "Scaling Relations for Piezoresistive Microphones", Proceedings of the ASME IMECE 2000, Orlando, FL, 2000.

${ }^{12}$ Arnold, D. P., “A MEMS-Based Directional Acoustic Array for Aeroacoustic Measurements”, Master's Thesis, University of Florida, Gainesville, FL, 2001.

${ }^{13}$ Schafer, D., Shoaf, S., and Loeppert, P., "Micromachined Condenser Microphone for Hearing Aid Use", Proceedings of the Solid-State Sensor and Actuator Workshop, pp. 27-30, 1998.

${ }^{14}$ Welch, P. D., "The Use of Fast Fourier Transform for the Estimation of Power Spectra: A Method Based on Time Averaging Over Short, Modified Periodograms”, IEEE Transactions on Audio Electroacoustics, Vol. AU-15, pp. 70-73, 1967.

${ }^{15}$ Mosher, M., Watts, M. E., Jaeger, S. M., and Jovic, S., "Calibration of Microphone Arrays for Phase Array Processing", AIAA Paper 97-1678, $3^{\text {rd }}$ AIAA/CEAS Aeroacoustics Conference, Atlanta, GA, 1997.

${ }^{16} \mathrm{Ngo}, \mathrm{K}$. C. T., and Zuckerwar, A. J., "Acoustic Isolation Vessel for Measurement of the Background Noise in Microphones", Journal of the Acoustical Society of America, Vol. 93, Number 5, pp. 2974-2980, 1993.

${ }^{17}$ Choi, K., and Simpson, R. L., "Some Mean Velocity, Turbulence and Unsteadiness Characteristics of the VPI\&SU Stability Wind Tunnel”, VPI-Aero-161, 1987.

${ }^{18}$ Dougherty, R. P., “Spiral-Shaped Array for Broadband Imaging”, U.S. Patent No. 5,838,284, 1998.

${ }^{19}$ Underbrink, J. R., "Circularly Symmetric, Zero Redundancy, Planar Array Having Broad Frequency Range Applications", U.S. Patent 6,205,224, 2001.

${ }^{20}$ Brooks, T. F., and Humphreys, W. M., Jr., "Effect of Directional Array Size on the Measurement of Airframe Noise Components", AIAA Paper 99-1958, $5^{\text {th }}$ AIAA Aeroacoustics Conference, Bellevue, WA, 1999.

${ }^{21}$ Johnson D. H., and Dudgeon, D. E., Array Signal Processing, Prentice-Hall, 1993.

${ }^{22}$ Horne, W. C., and James, K. D., "Concepts for Reducing the Self-Noise of In-Flow Acoustic Sensors and Arrays", AIAA Paper 99-1815, $5^{\text {th }}$ AIAA/CEAS Aeroacoustics Conference, Bellevue, WA, 1999.

${ }^{23}$ Jaeger, S. M., Horne, W. C., and Allen, C. S., "Effect of Surface Treatment on Array Microphone Self-Noise", AIAA Paper 2000-1937, $6^{\text {th }}$ AIAA/CEAS Aeroacoustics Conference, Lahaina, HI, 2000.

${ }^{24}$ Amiet, R. K., "Refraction of Sound by a Shear Layer", Journal of Sound and Vibration, Vol. 58, No. 3, pp. 467-482, 1978. 
${ }^{25}$ Brooks, T. F., and Humphreys, W. M., Jr., "A Deconvolution Approach for the Mapping of Acoustic Sources (DAMAS) Determined from Phased Microphone Arrays", AIAA Paper 2004-2954, $10^{\text {th }}$ AIAA/CEAS Aeroacoustics Conference, Manchester, U.K., 2004.

${ }^{26}$ Brooks, T. F., and Humphreys, W. M., Jr., "Some Three-Dimensional Applications of DAMAS Methodology for Aeroacoustic Noise Source Definition”, AIAA Paper 2005-2960, $11^{\text {th }}$ AIAA/CEAS Aeroacoustics Conference, Monterey, CA, 2005.

\section{Appendix I - MEMS Array Coordinates}

\begin{tabular}{|c|c|c|c|c|c|c|c|c|}
\hline Mic \# & X location & Y location & Mic \# & X location & Y location & Mic \# & X location & Y location \\
\hline & (in) & (in) & & (in) & (in) & & (in) & (in) \\
\hline 1 & 1.00 & 0.00 & 44 & 6.38 & -4.40 & 87 & 11.46 & -6.85 \\
\hline 2 & 0.92 & 0.38 & 45 & 7.58 & -1.63 & 88 & 13.21 & -1.94 \\
\hline 3 & 0.71 & 0.71 & 46 & 7.62 & 1.40 & 89 & 12.94 & 3.26 \\
\hline 4 & 0.38 & 0.92 & 47 & 6.51 & 4.21 & 90 & 10.71 & 7.97 \\
\hline 5 & 0.00 & 1.00 & 48 & 4.40 & 6.38 & 91 & 6.85 & 11.46 \\
\hline 6 & -0.38 & 0.92 & 49 & -6.65 & 7.44 & 92 & 1.94 & 13.21 \\
\hline 7 & -0.71 & 0.71 & 50 & -8.99 & 4.33 & 93 & -3.26 & 12.94 \\
\hline 8 & -0.92 & 0.38 & 51 & -9.96 & 0.56 & 94 & -7.97 & 10.71 \\
\hline 9 & -1.00 & 0.00 & 52 & -9.41 & -3.29 & 95 & -11.46 & 6.85 \\
\hline 10 & -0.92 & -0.38 & 53 & -7.44 & -6.65 & 96 & -13.21 & 1.94 \\
\hline 11 & -0.71 & -0.71 & 54 & -4.33 & -8.99 & 97 & -12.01 & -8.56 \\
\hline 12 & -0.38 & -0.92 & 55 & -0.56 & -9.96 & 98 & -7.82 & -12.51 \\
\hline 13 & 0.00 & -1.00 & 56 & 3.29 & -9.41 & 99 & -2.44 & -14.55 \\
\hline 14 & 0.38 & -0.92 & 57 & 6.65 & -7.44 & 100 & 3.32 & -14.37 \\
\hline 15 & 0.71 & -0.71 & 58 & 8.99 & -4.33 & 101 & 8.57 & -12.01 \\
\hline 16 & 0.92 & -0.38 & 59 & 9.96 & -0.56 & 102 & 12.51 & -7.82 \\
\hline 17 & 3.68 & -2.68 & 60 & 9.41 & 3.29 & 103 & 14.55 & -2.44 \\
\hline 18 & 4.42 & -1.07 & 61 & 7.44 & 6.65 & 104 & 14.37 & 3.32 \\
\hline 19 & 4.49 & 0.71 & 62 & 4.33 & 8.98 & 105 & 12.01 & 8.57 \\
\hline 20 & 3.88 & 2.37 & 63 & 0.56 & 9.96 & 106 & 7.82 & 12.51 \\
\hline 21 & 2.68 & 3.68 & 64 & -3.29 & 9.41 & 107 & 2.44 & 14.55 \\
\hline 22 & 1.07 & 4.42 & 65 & -11.50 & 2.56 & 108 & -3.32 & 14.37 \\
\hline 23 & -0.71 & 4.49 & 66 & -11.61 & -2.04 & 109 & -8.57 & 12.01 \\
\hline 24 & -2.37 & 3.88 & 67 & -9.94 & -6.32 & 110 & -12.51 & 7.82 \\
\hline 25 & -3.68 & 2.68 & 68 & -6.77 & -9.65 & 111 & -14.55 & 2.44 \\
\hline 26 & -4.42 & 1.07 & 69 & -2.56 & -11.50 & 112 & -14.37 & -3.32 \\
\hline 27 & -4.49 & -0.71 & 70 & 2.04 & -11.61 & 113 & -9.58 & -12.85 \\
\hline 28 & -3.88 & -2.37 & 71 & 6.32 & -9.94 & 114 & -3.94 & -15.54 \\
\hline 29 & -2.68 & -3.68 & 72 & 9.65 & -6.77 & 115 & 2.31 & -15.86 \\
\hline 30 & -1.07 & -4.42 & 73 & 11.50 & -2.56 & 116 & 8.20 & -13.77 \\
\hline 31 & 0.71 & -4.49 & 74 & 11.61 & 2.04 & 117 & 12.85 & -9.58 \\
\hline 32 & 2.37 & -3.88 & 75 & 9.94 & 6.32 & 118 & 15.54 & -3.94 \\
\hline 33 & 1.63 & 7.58 & 76 & 6.77 & 9.65 & 119 & 15.86 & 2.31 \\
\hline 34 & -1.40 & 7.62 & 77 & 2.56 & 11.50 & 120 & 13.77 & 8.20 \\
\hline 35 & -4.21 & 6.51 & 78 & -2.04 & 11.61 & 121 & 9.59 & 12.85 \\
\hline 36 & -6.38 & 4.40 & 79 & -6.32 & 9.94 & 122 & 3.94 & 15.54 \\
\hline 37 & -7.58 & 1.63 & 80 & -9.65 & 6.77 & 123 & -2.31 & 15.86 \\
\hline 38 & -7.62 & -1.40 & 81 & -12.95 & -3.26 & 124 & -8.20 & 13.77 \\
\hline 39 & -6.51 & -4.21 & 82 & -10.71 & -7.97 & 125 & -12.85 & 9.58 \\
\hline 40 & -4.40 & -6.38 & 83 & -6.85 & -11.46 & 126 & -15.54 & 3.94 \\
\hline 41 & -1.63 & -7.58 & 84 & -1.94 & -13.21 & 127 & -15.86 & -2.31 \\
\hline 42 & 1.40 & -7.62 & 85 & 3.26 & -12.94 & 128 & -13.77 & -8.20 \\
\hline 43 & 4.21 & -6.51 & 86 & 7.97 & -10.71 & & & \\
\hline
\end{tabular}

11

American Institute of Aeronautics and Astronautics 


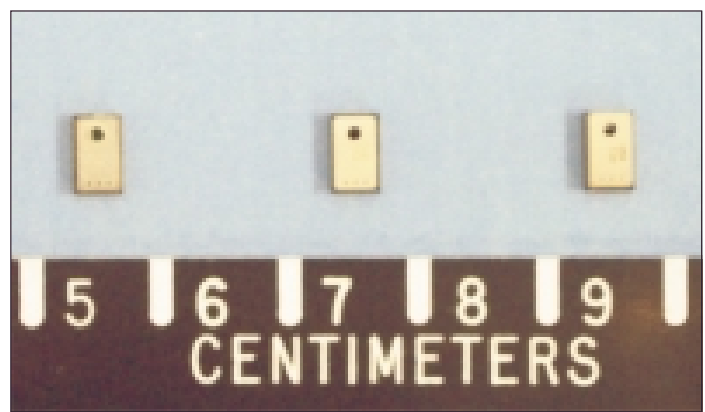

(a)

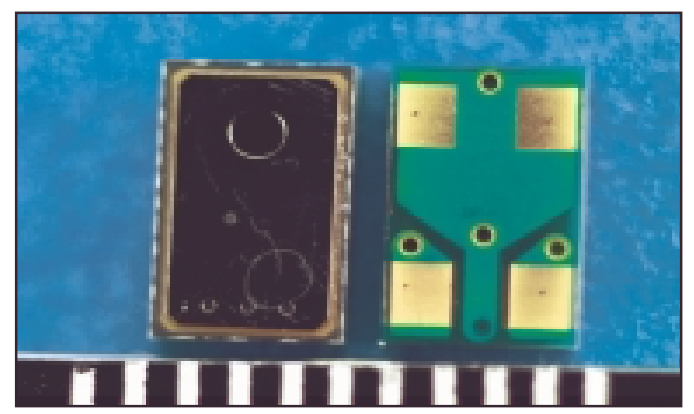

(b)

Figure 1. SP0101NZ MEMS Microphones.

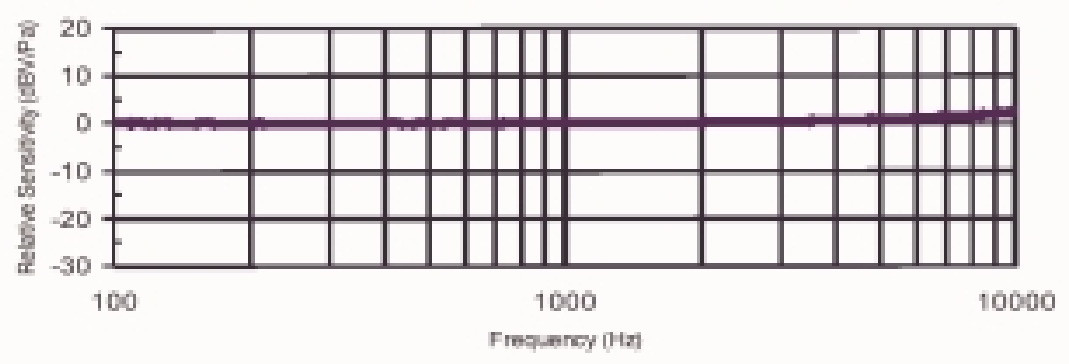

Figure 2. Manufacturer's Typical SP0101NZ Sensitivity Response.

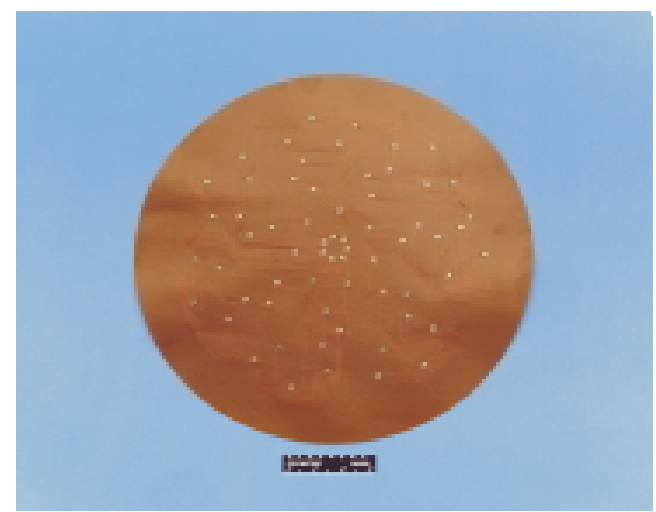

Figure 3. Prototype Kapton Sheet Containing 63 MEMS Microphones.

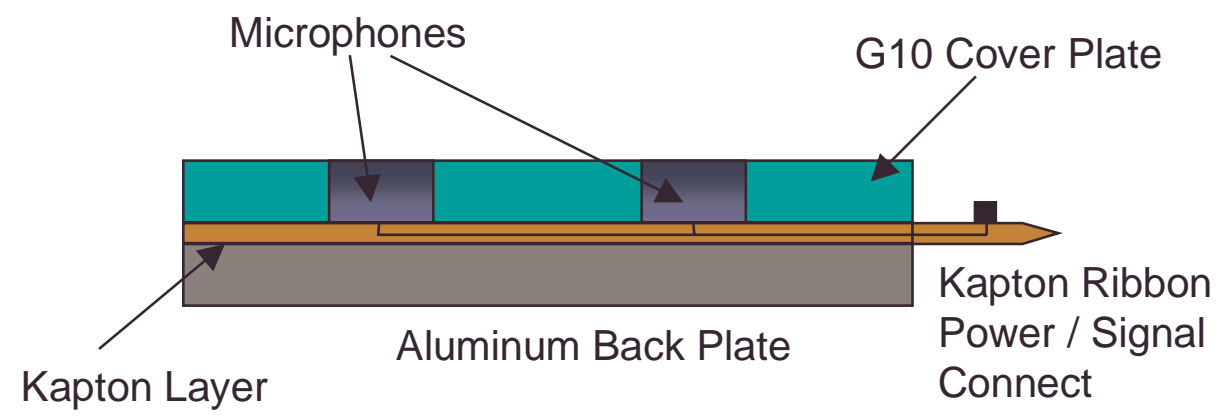

Figure 4. Cross Section Diagram of Array Panel Fabrication. 


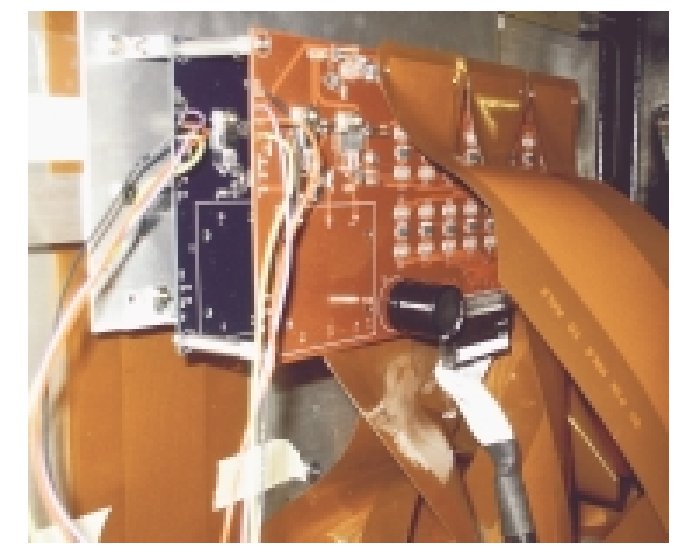

Figure 5. Line Driver Circuitry.

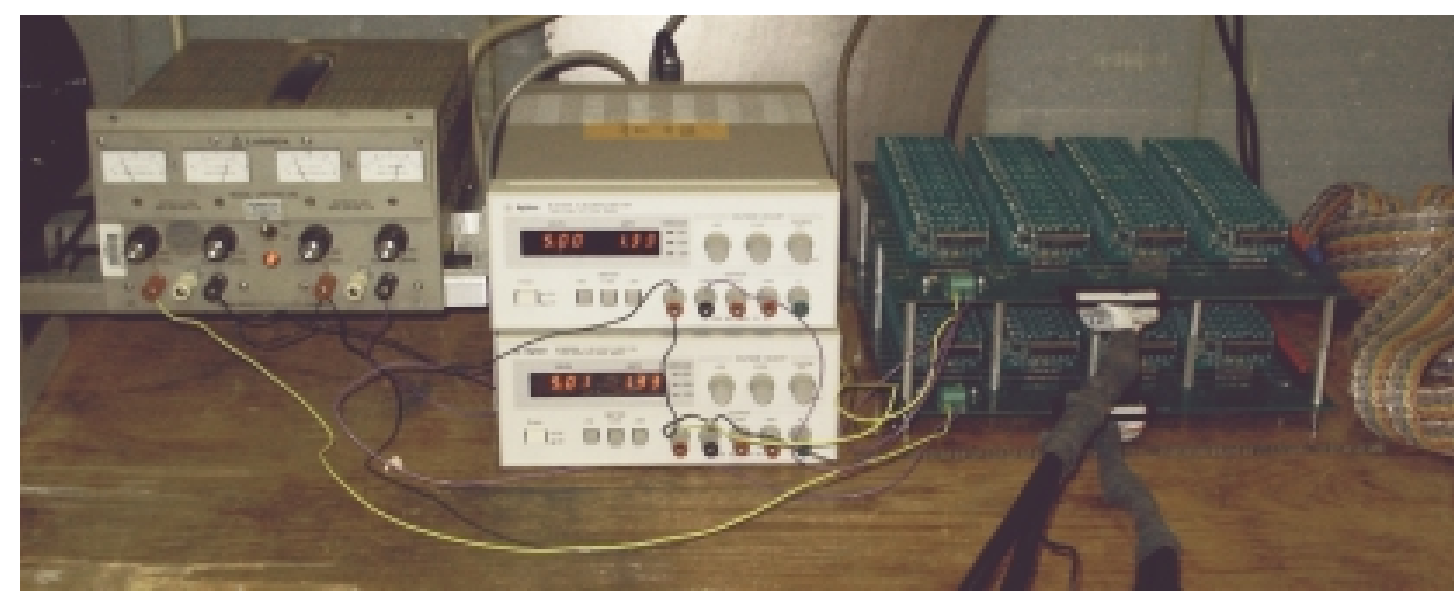

Figure 6. Anti-alias Filtering Hardware.

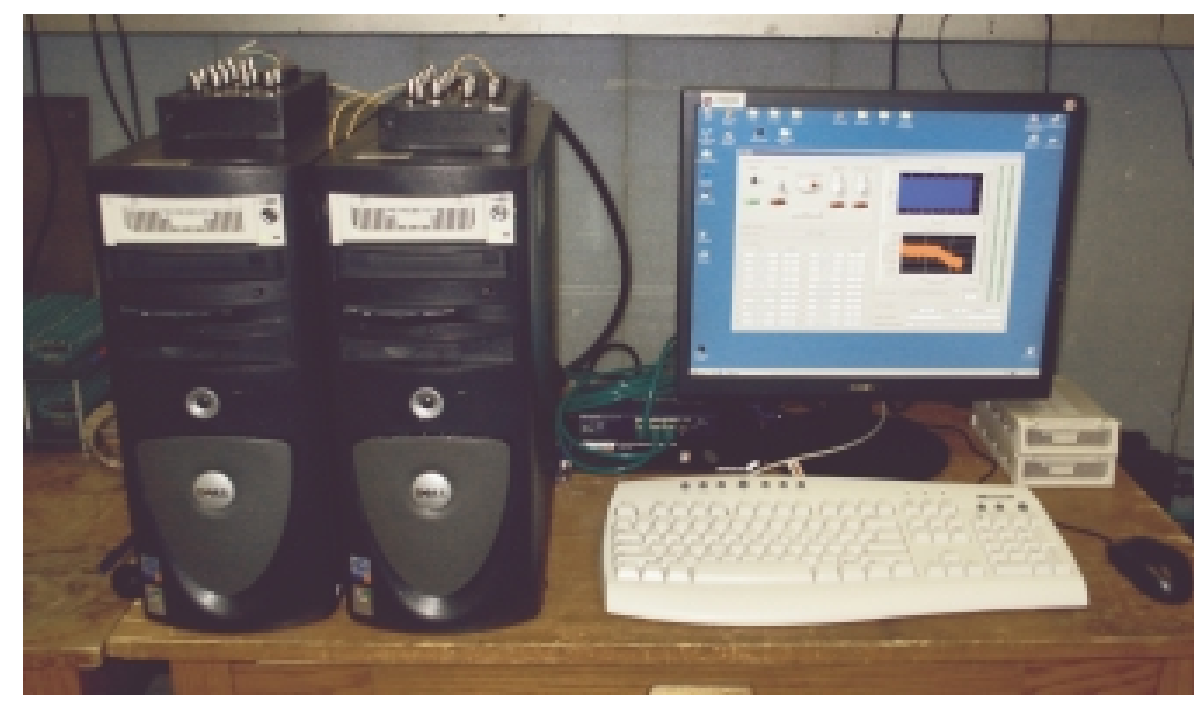

Figure 7. Distributed (Two-Node) Data Acquisition System.

American Institute of Aeronautics and Astronautics 


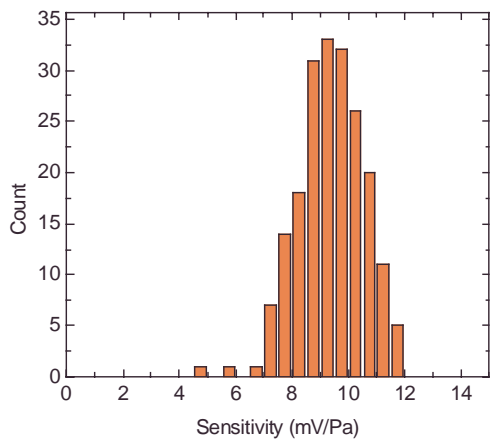

Figure 8. Sensitivity Histogram for Ensemble of 200 Microphones.

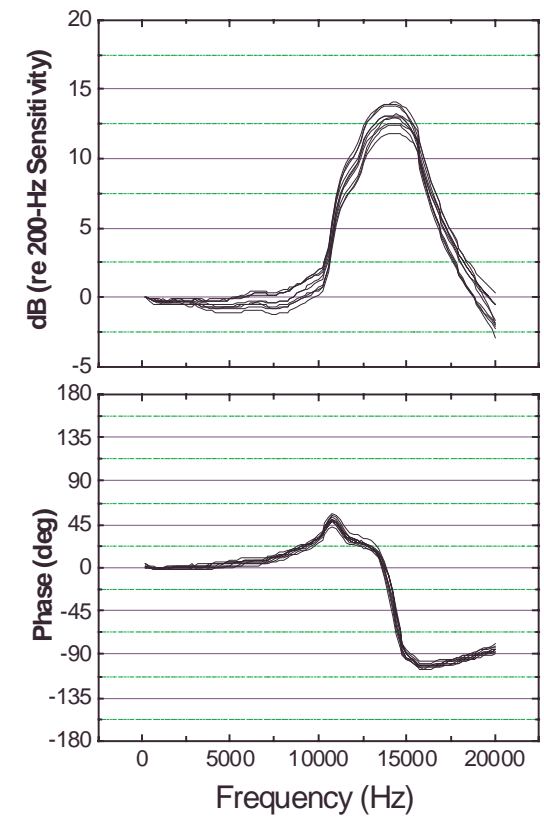

Figure 9. Broadband Frequency Response for 10 Representative Microphones.

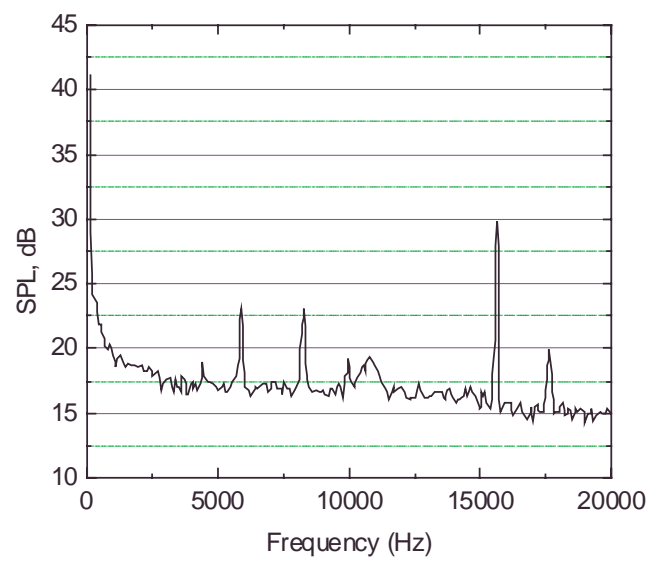

Figure 10. Background Electrical Noise of Representative Microphone.

American Institute of Aeronautics and Astronautics 


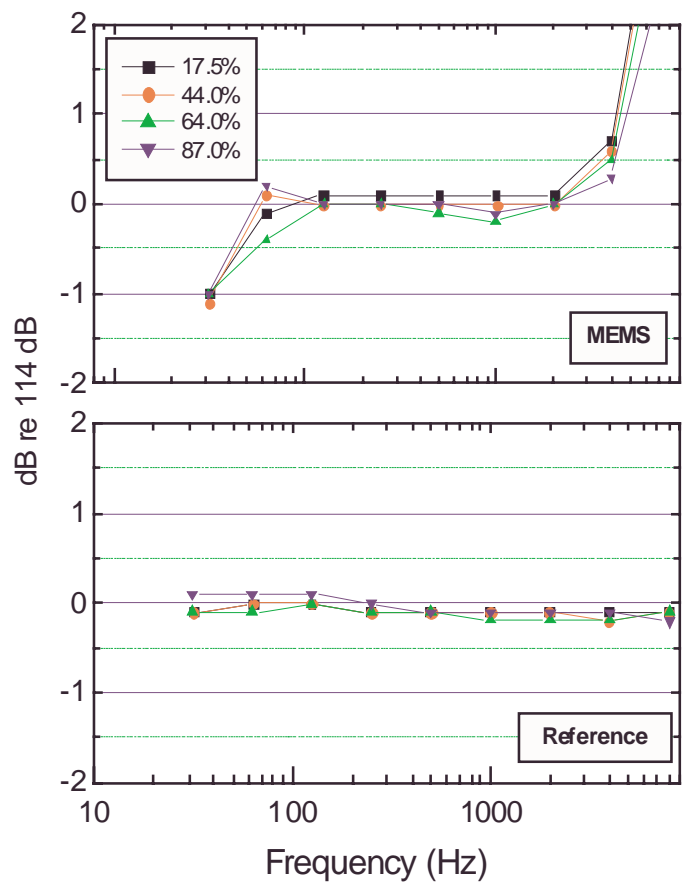

Figure 11. Variation in Sensitivity with Percent Humidity.

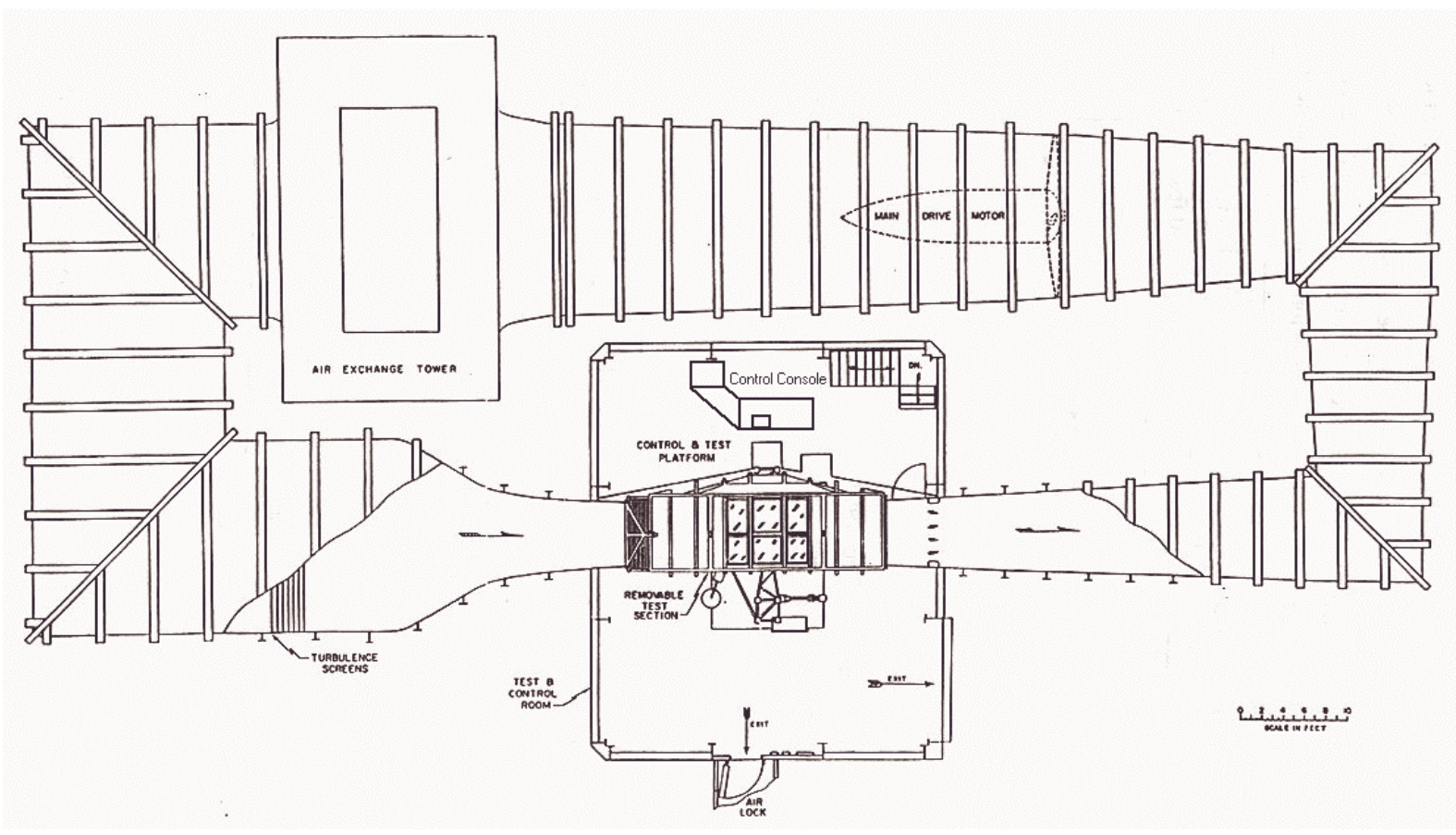

Figure 12. Virginia Tech Stability Tunnel. 


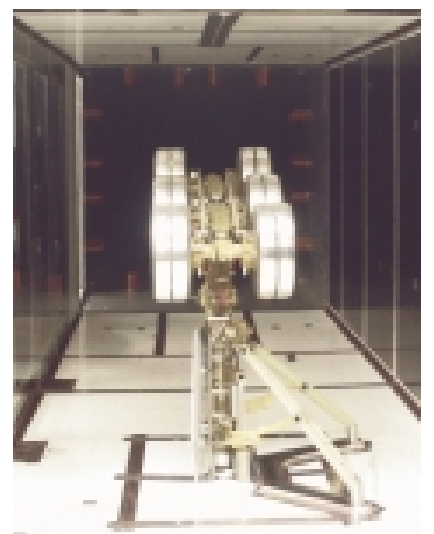

Figure 13. 26\% -scale, High-Fidelity B777 Main Landing Gear.

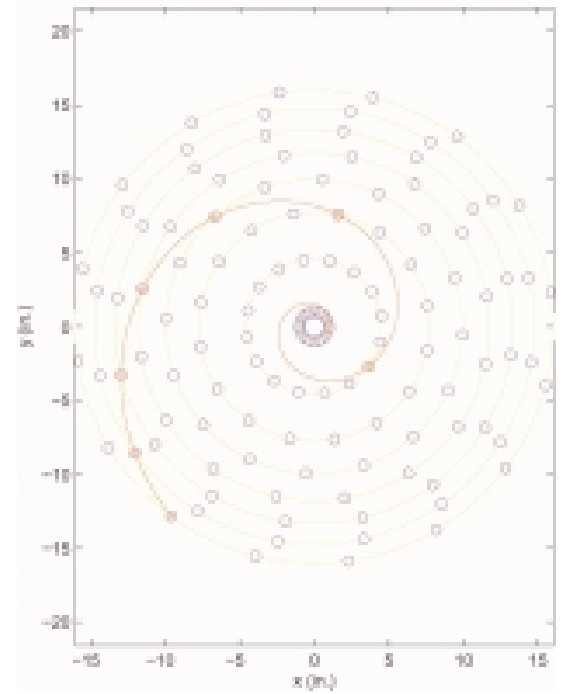

Figure 14. MEMS Array Layout.
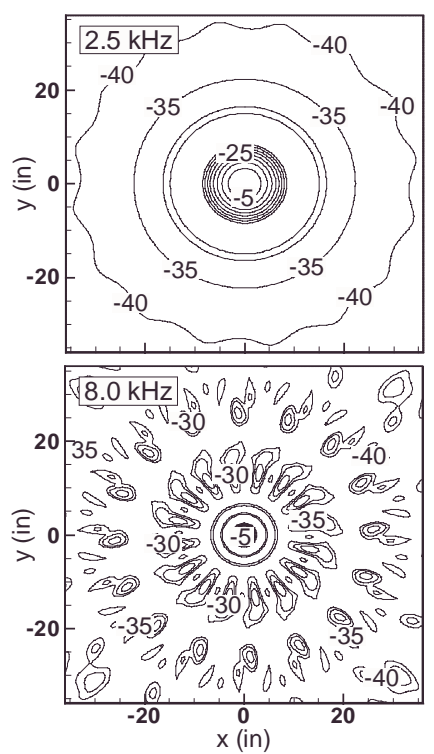

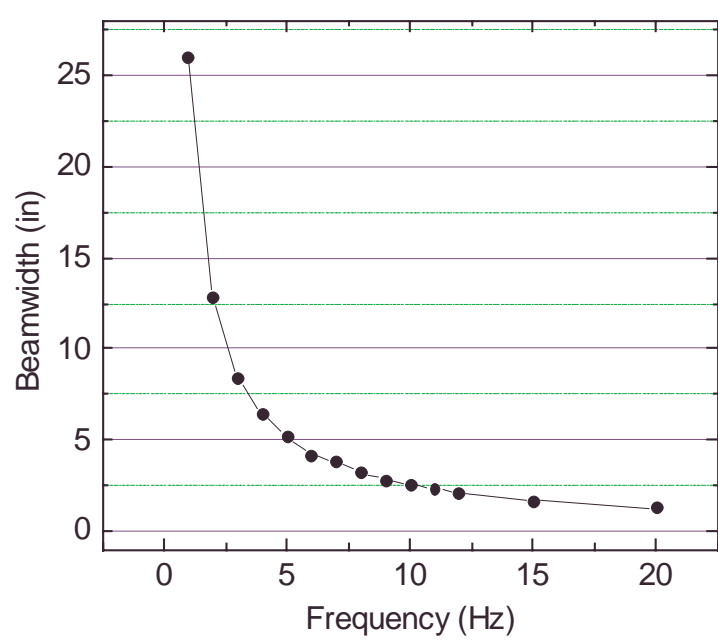

Figure 15. Array Beamwidth versus Frequency for Source 3 Feet in Front of Array.
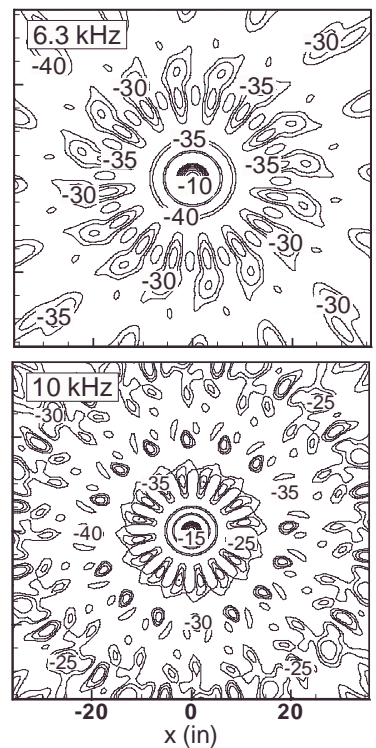

Figure 16. Monopole Response for Source Located 3 Feet in Front of Array. 

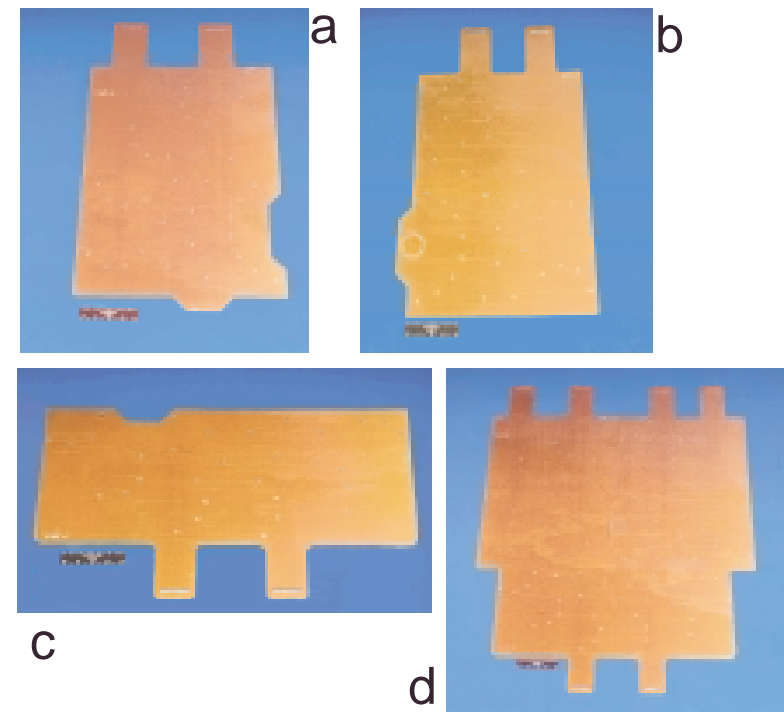

Figure 17. Three Individual Kapton Panels Fitted for Form Final Array $(a+b+c=d)$.

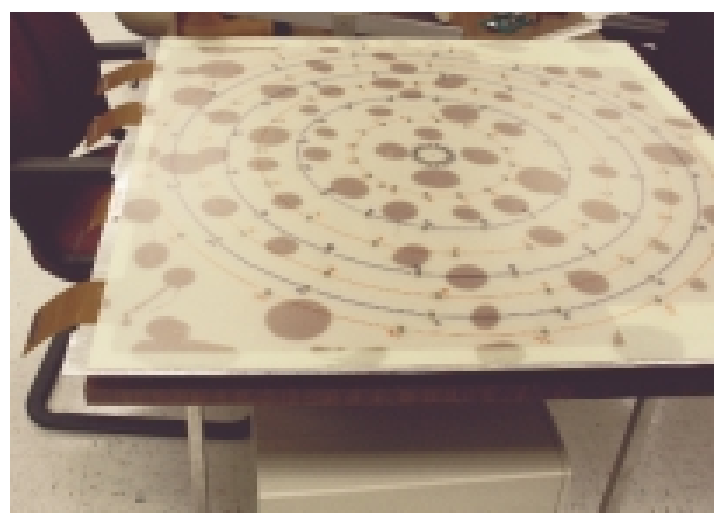

Figure 18. Completed MEMS Array Panel.
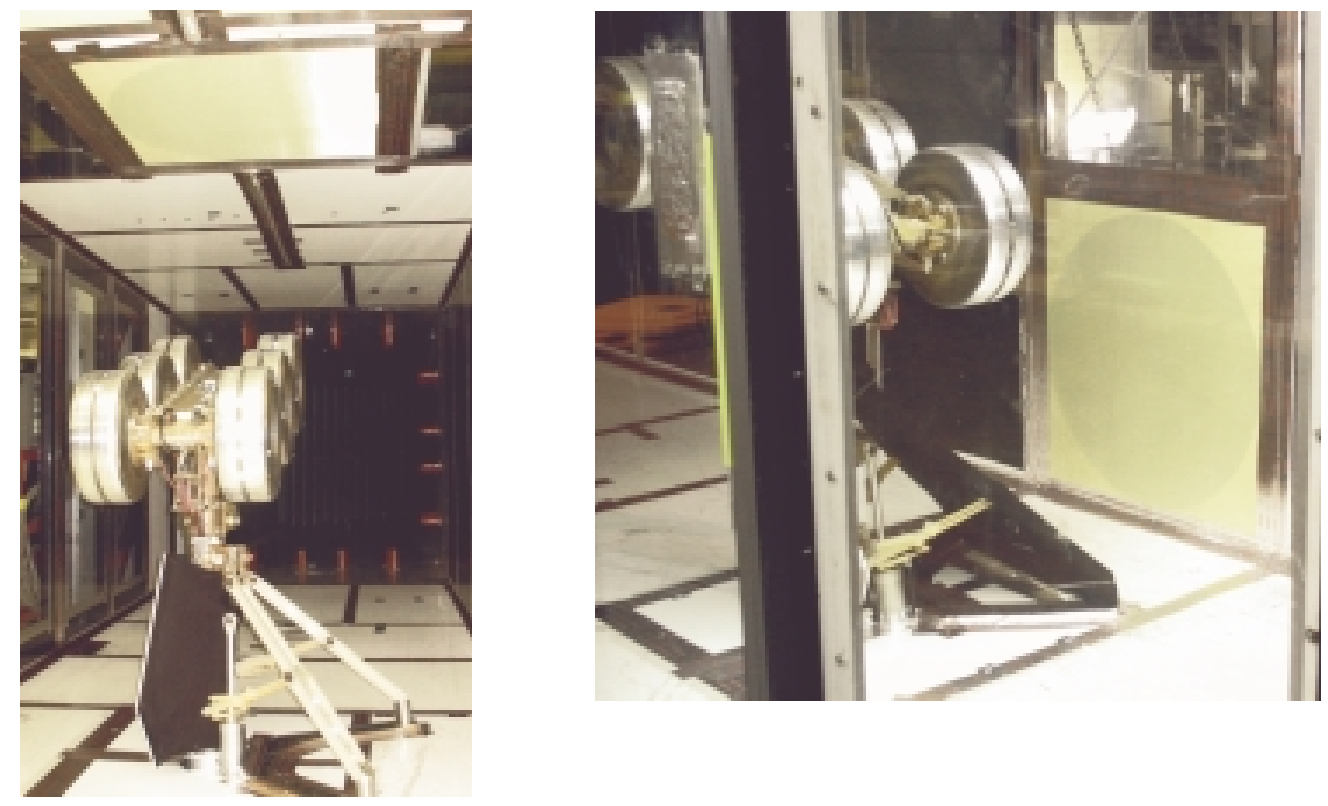

Figure 19. Kevlar-covered MEMS Array Mounted in VT Stability Tunnel. Left - Flyover View, Right - Strut Brace View. 

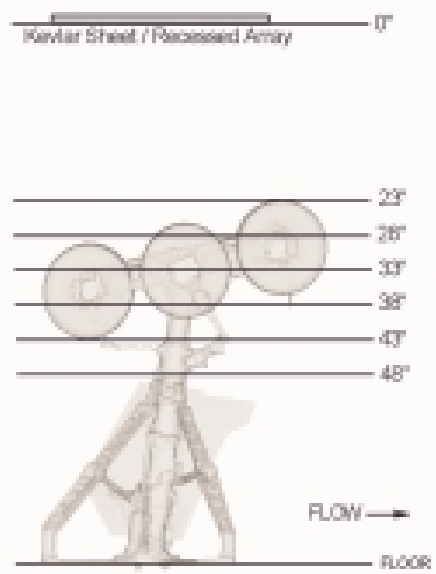

Figure 20. Defined Flyover Beamforming Planes.
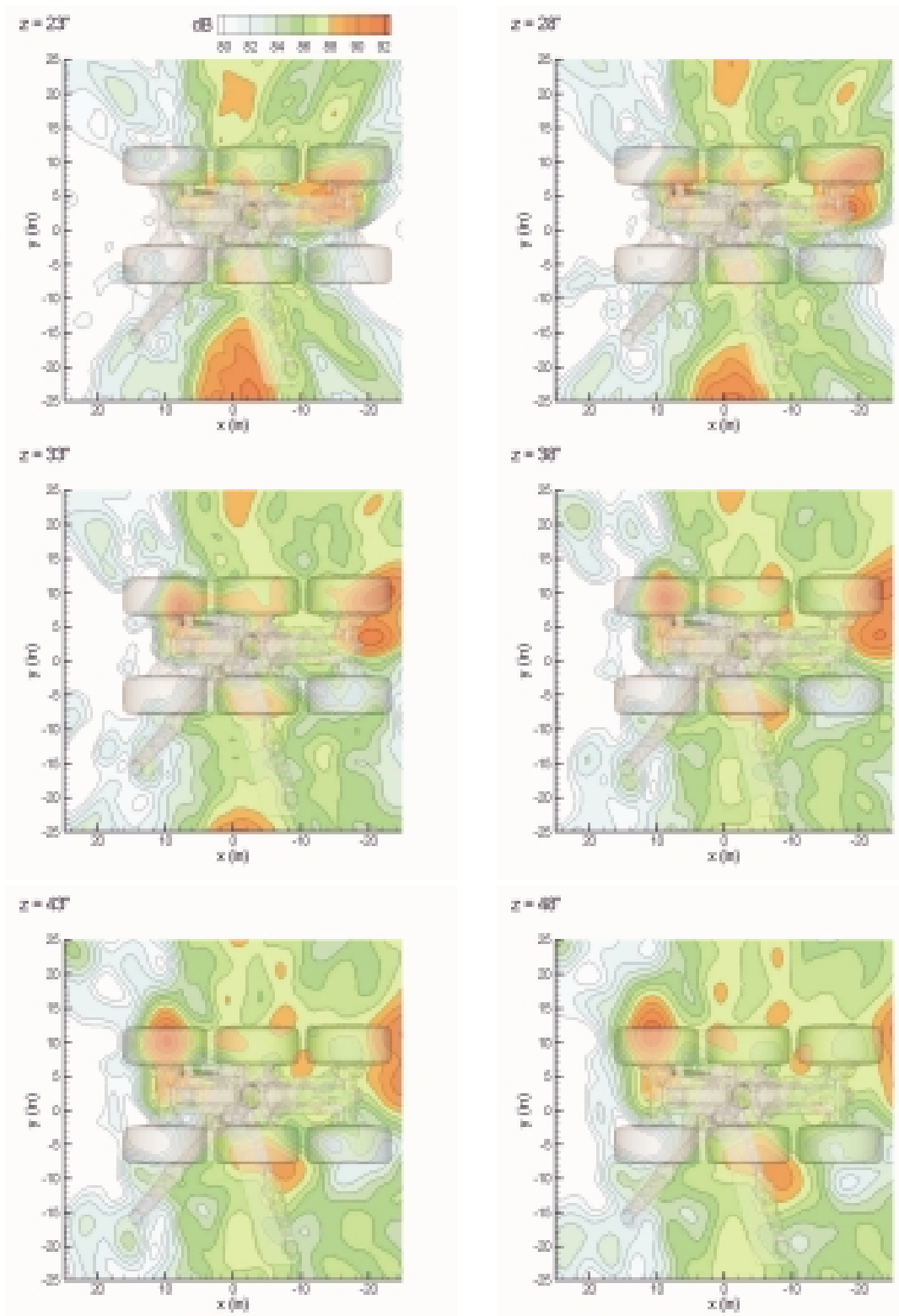

Figure 21. Flyover Noise Location Maps, $\mathbf{f}_{1 / 3}=6.3 \mathrm{kHz}$, for Planes Defined in Figure 20 .

American Institute of Aeronautics and Astronautics 


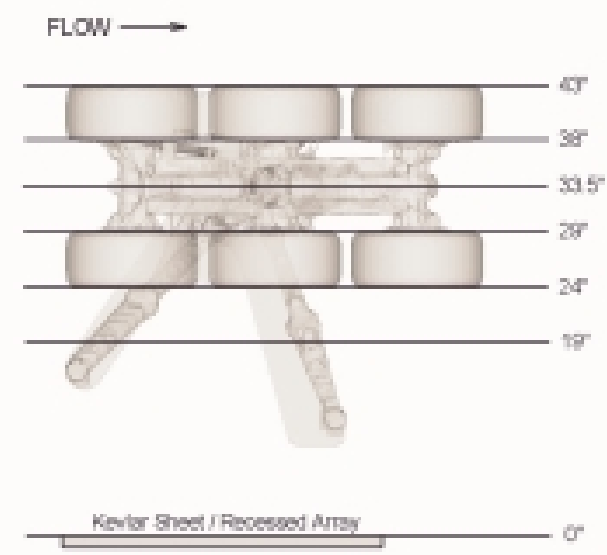

Figure 22. Defined Sideview Beamforming Planes.
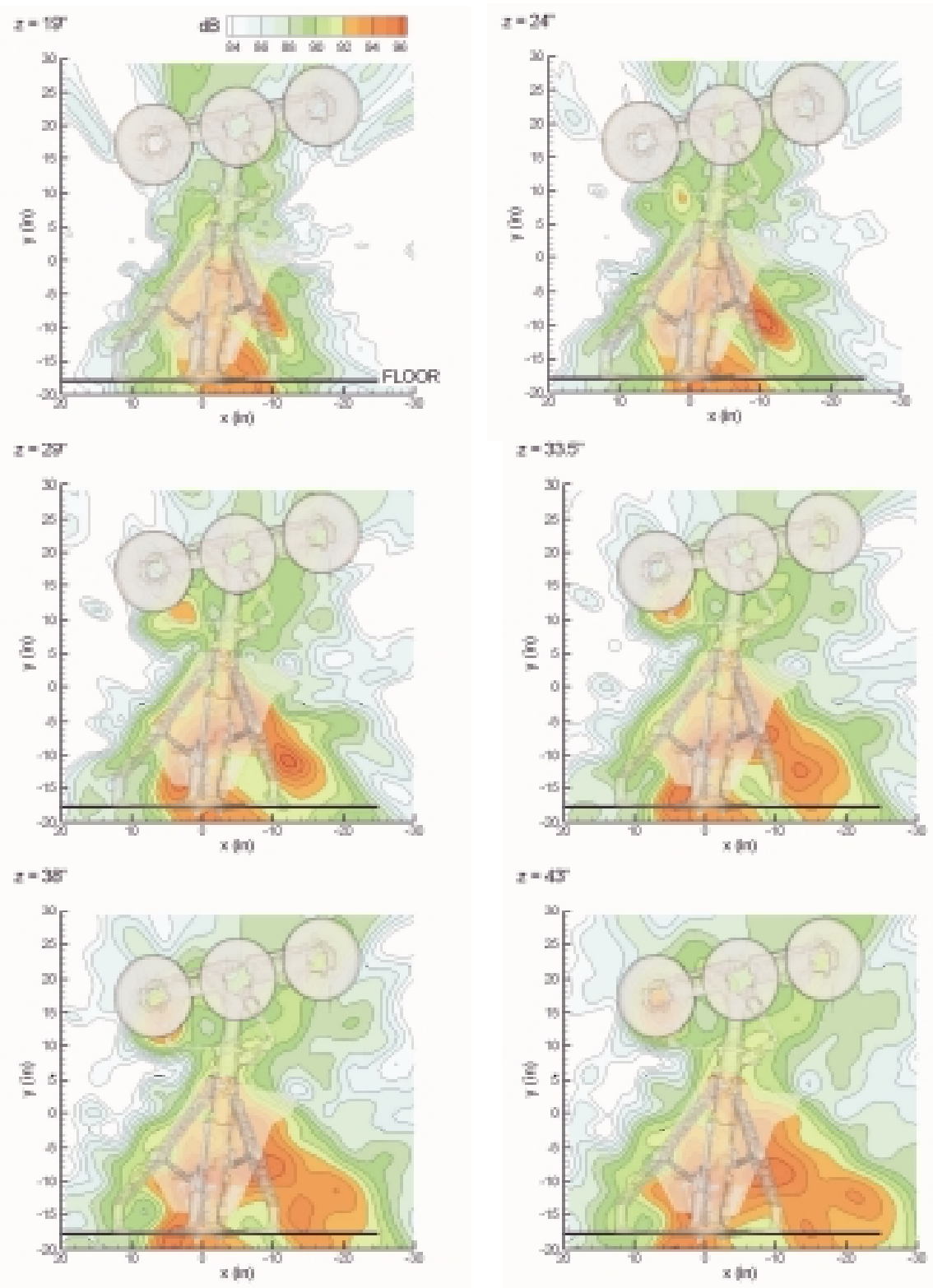

Figure 23. Sideview Noise Location Maps, $\mathbf{f}_{1 / 3}=6.3 \mathrm{kHz}$, for Planes Defined in Figure 22 . 

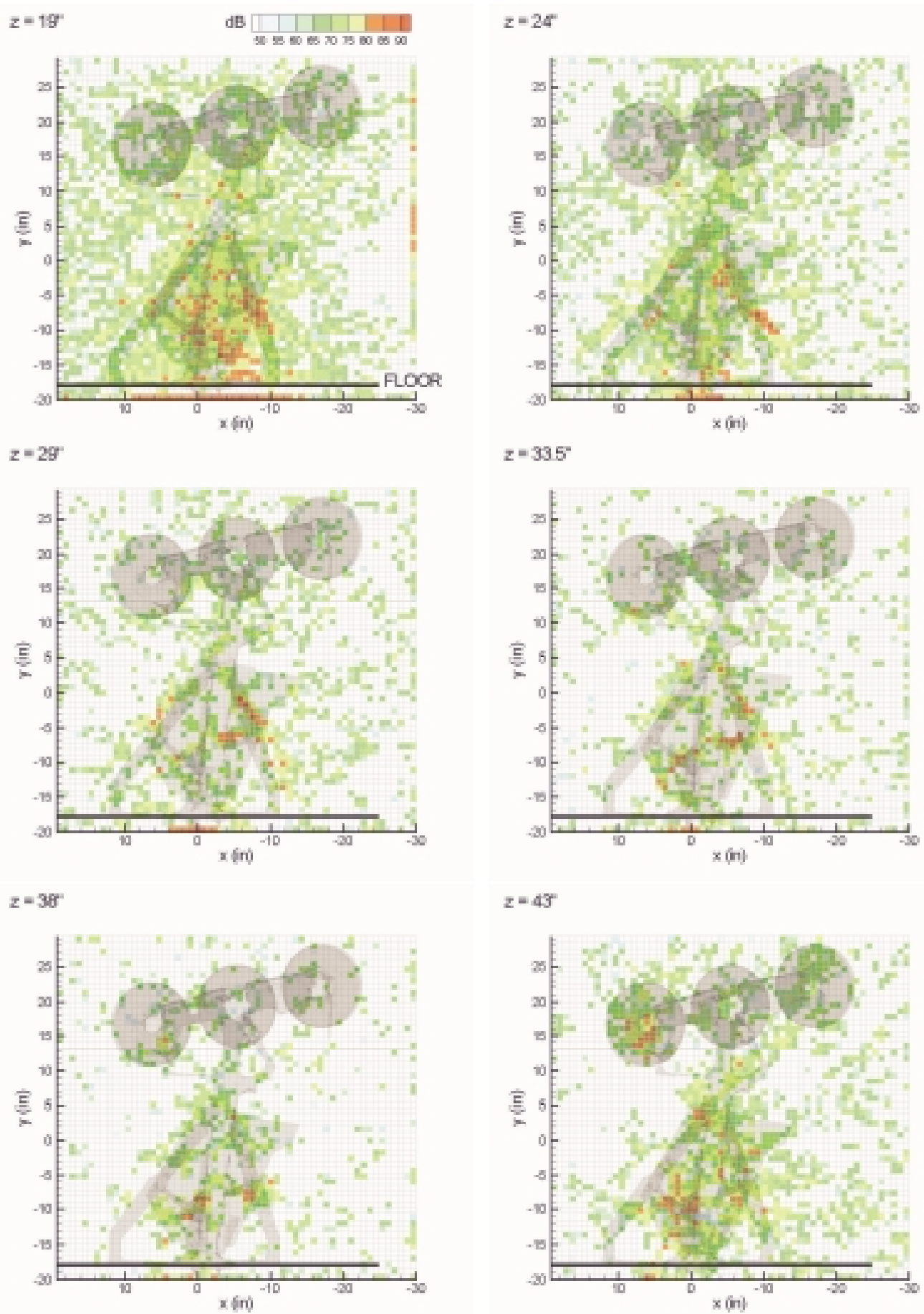

Figure 24. Corresponding 3D DAMAS Output for Sideview Noise Location Maps Shown in Figure 23. 